\title{
A Study on Strength and Xrd Analysis of Carbonated Concrete
}

\author{
M.Jothilingam ${ }^{1}$, Dr. Pratheeba Paul ${ }^{2}$ \\ 1. Assistant Professor ( S.G.), Dept. of Civil Engineering, SRM Institute of Science and Technology, \\ 2. Professor ,Dept.of Civil Engineering, Hindustan Institute of Technology and Science, Padur, Chennai. \\ *Corresponding authorE-mail: lingam7907@gmail.com
}

\begin{abstract}
There are number of factors which control the rate of process of natural carbonation and make it very slow in cement based material. Studies show that the effect of carbonation is mostly limited to corrosion of steel reinforcement in R.C.C. structures (including cover depth design and service life prediction). Research at global level is focused on developing a cost effective and safe technology for the possibility of carbon dioxide sequestration as per IPCC guide lines, and attempts are being made to apply the accelerated carbonation technology for $\mathrm{CO} 2$ sequestration in concrete. This paper discusses about the detailed study on the uptake quantity of carbon dioxide in concrete, increase of strength and changes in mineral content by adopting. The concrete grades of M15, M20, M25 and M30 were taken for investigating the strength with respect to time of exposure and pressure by adopting Accelerated Carbonation Technology by using commercially available pure $\mathrm{CO} 2$ for carbonation curing. After the testing of concrete for strength, XRD analysis was carried out to study the conversion of calcium hydroxide into calcium carbonate due to carbonation. This green technology would help cement, concrete, precast product and other similar manufacturing industries to obtain carbon credit and they can adopt this green technology to reduce their industrial carbon dioxide emissions into the atmosphere to reduce global warming.
\end{abstract}

Keywords: Carbonation curing, Cover depth, CO2 sequestration, carbon uptake and credit.

\section{Introduction}

The global warming and climate change due to emission of $\mathrm{CO} 2$ (the principal greenhouse gas) from Cement industries worldwide can be reduced by $18 \%$ in the year 2050 by adopting the technology roadmap of IEA\& IPCC which envisages energy efficiency, alternative fuel, clinker substitution, Carbon Capture and Sequestration in geological, ocean, enhanced oil recovery, abandoned coal field, mineral conversion and concrete [7,9]. In the cement industries, $\mathrm{CO} 2$ from flue gas (14\% by volume) can be captured by adopting suitable novel technologies like oxy-fuel combustion and Mono-Ethanol Amine/ Methyl-di-Ethanol Amine scrubbing and self-concentration absorption technique[4, 11]. Among the available $\mathrm{CO} 2$ capturing technologies, the calcium looping cycle can be preferably adopted economically with minimal limestonerelated infrastructure investment, since lime stone is a cheap material with good geographical distribution and is already being used for cement manufacture. The potential benefit of this new technology is that the lime purged from the cycle could be used as a raw material for the production of cement clinker and the cost of $\mathrm{CO} 2$ capture can be considerably reduced. Further, very low efficiency penalty is expected $(<6 \%)$ compared with other capture technologies [1]. The current trading value of $\mathrm{CO} 2$ is between 4 and 41 USD per ton in US, Canada and Europe. Each year the potential for capturing $\mathrm{CO} 2$ from the atmosphere (through concrete) is roughly estimated at 266 million tons worldwide [8].

Carbonation is a process which takes place while $\mathrm{Ca}(\mathrm{OH}) 2$ present in the concrete reacts with $\mathrm{CO} 2$ available in the air $(0.033 \%$ by volume or $350 \mathrm{ppm}$ ), right from the starting of mixing operation and converted as thermodynamically stable calcium carbonate and so reduces the atmospheric concentration. This is a slow and continuous process which is working from the surface of the concrete inward. The estimated quantity of $\mathrm{CO} 2$ uptake in plain cement concrete produced with cement content of $350 \mathrm{~kg}$ per cubic meter would be $10 \mathrm{~kg}$ ( $3 \%$ by weight of cement used) during the initial stage and $65 \mathrm{~kg}(19 \%)$ in fully carbonated stage and differs according to the mix proportions and admixtures added .The $\mathrm{CO} 2$ sequestration is a new opportunity for carbon trading, evidence for environmental reporting and production of high potential building materials. The annual sequestration potential is forecast based on cement utilization for the construction concrete products being marketed in U.S. and Canada and the details are furnished in the Table 1. [12].

Table 1: $\mathrm{CO}_{2}$ Sequestration potential of materials in U.S. \& Canada

\begin{tabular}{|l|c|c|c|c|}
\hline Description & $\begin{array}{l}\text { Masonry } \\
\text { Block }\end{array}$ & $\begin{array}{l}\text { Paver } \\
\text { Block }\end{array}$ & $\begin{array}{l}\text { Cement } \\
\text { Board }\end{array}$ & $\begin{array}{l}\text { Fiber } \\
\text { Board }\end{array}$ \\
\hline Annual production & $\begin{array}{c}4.3 \times 10^{9} \\
\text { Nos. }\end{array}$ & $\begin{array}{c}74 \times 10^{6} \\
\mathrm{~m}^{2}\end{array}$ & $75 \times 10^{6} \mathrm{~m}^{2}$ & $\begin{array}{c}9.1 \times 10^{8} \\
\mathrm{~m}^{2}\end{array}$ \\
\hline $\begin{array}{l}\text { Cement used (Million } \\
\text { tons) } \\
\mathbf{1 3 . 8 9 5 M t}\end{array}$ & 5.900 & 2.600 & 0.595 & 4.800 \\
\hline $\begin{array}{l}\text { Uptake from recov- } \\
\text { ered CO}(9.8-18.9 \%) \\
=\mathbf{1 . 8 1 3} \text { Mt }\end{array}$ & 0.578 & 0.255 & 0.073 & 0.907 \\
\hline $\begin{array}{l}\text { Uptake from flue gas } \\
(6.3-8.1 \%) \\
\mathbf{0 . 9 5 1} \text { Mt }\end{array}$ & 0.372 & 0.164 & 0.026 & 0.389 \\
\hline
\end{tabular}

It was reported in the literature that the building products like plain cement concrete masonry block, paver block, cement board and fiber board treated with accelerated carbonation curing en- 
hances early strength gain, durability, shortening of curing time, reduced water permeability and it is also good in freeze- thaw cycling effect. The uptake quantity of $\mathrm{CO} 2$ with concrete by using pure gas is twice that of flue gas [12]. The energy cost of steam curing and carbonation curing study on a light weight P.C.C. hollow block $(15 \mathrm{~kg})$, worked out to $9.84 \mathrm{USD} / \mathrm{cu} . \mathrm{m}$ and 9.27 USD/cu.m respectively. The existing steam curing plant can be modified to make it suitable for carbonation curing at reasonable cost $[3,5,6]$. Replacing $10 \%$ of building materials with carbonated minerals is expected to reduce $\mathrm{CO} 2$ emissions by $1.6 \mathrm{Gt} / \mathrm{year}$ of the global CO2 emission as of 2011 [2].

\section{Mechanism of Carbonation}

The mechanism of accelerated carbonation due to the reaction of $\mathrm{CO} 2$ with tri-calcium silicate and di-calcium silicate was described by the researcher as detailed below [10].

$$
\begin{aligned}
& \mathrm{C}_{3} \mathrm{~S}+3 \mathrm{CO}_{2}+\mathrm{H}_{2} \mathrm{O} \rightarrow \mathrm{C}-\mathrm{S}-\mathrm{H}+3 \mathrm{CaCO}_{3}+347 \mathrm{~kJ} / \mathrm{mol} \\
& \mathrm{C}_{2} \mathrm{~S}+2 \mathrm{CO}_{2}+\mathrm{H}_{2} \mathrm{O} \rightarrow \mathrm{C}-\mathrm{S}-\mathrm{H}+2 \mathrm{CaCO}_{3}+184 \mathrm{~kJ} / \mathrm{mol}
\end{aligned}
$$

The steps involved in the exothermic reactions are at nine stages: Diffusion of $\mathrm{CO}_{2}$ gas in to concrete, permeation of $\mathrm{CO}_{2}$ through the air filled pores of concrete, transformation of $\mathrm{CO}_{2}$ from gas phase to aqueous phase of concrete in the plastic stage and subsequently converted to $\mathrm{H}_{2} \mathrm{CO}_{3}$, ionization of $\mathrm{H}_{2} \mathrm{CO}_{3}$ to $\mathrm{H}^{+}, \mathrm{HCO}_{3}{ }^{-}$, $\mathrm{CO}_{3}{ }^{2-}$ and the drop of $\mathrm{pH}$ due to $\mathrm{H}^{+}$can recover due to development of micro structure. Dissolution of $\mathrm{C}_{3} \mathrm{~S}$ and $\mathrm{C}_{2} \mathrm{~S}$ yields $\mathrm{C}-\mathrm{S}-\mathrm{H}$ gel that dissolves to release $\mathrm{Ca}^{2+}$ and $\mathrm{SiO}_{4}{ }^{4-}$ ions, Nucleation of stable $\mathrm{CaCO}_{3}$ and formation of C-S-H gel in a conventional manner, precipitation of $\mathrm{CaCO}_{3}$ as solid phase and secondary reaction of carbonation with remaining cement paste producing Calcium Silicate Hydration and $\mathrm{CaCO}_{3}$

\section{Materials and Methods}

\subsection{Materials}

Ordinary Portland Cement 53 grade conforming to IS: 12269 1987, river sand with fineness modulus 3.13 and coarse aggregate with fineness modulus 7.2, potable water and pure carbon dioxide were the materials used in this study. Specific gravity of coarse and fine aggregates are 2.74 and 2.63, respectively.

\subsection{Design Mix and Propotion}

The mix proportion for M15, M20, M25 and M30 is adopted as per IS-10262-2009. The experimental program was designed to study the compressive strength and $\mathrm{CO}_{2}$ sequestration by accelerated carbonation test. The maximum size coarse aggregate was limited to $20 \mathrm{~mm}$. Sieve analysis conforming to IS: 383-1970 was carried for both fine and coarse aggregate. The concrete mix design was proposed to achieve the compressive strength of $15 \mathrm{MPa}$ $20 \mathrm{MPa}, 25 \mathrm{MPa}$ and $30 \mathrm{MPa}$ after 28 days of curing in the case of cubes and the details are furnished in Table 2. The concrete cubes of size $(100 \times 100 \times 100 \mathrm{~mm})$ were cast and demoulded after $24 \mathrm{hrs}$. Among the specimens were cast $50 \%$ utilized as a reference concrete and $50 \%$ for carbonation purpose. The reference specimens were water cured and tested at room temperature at the age of 7 , 14 and 28 days.

\subsection{Accelerated Carbonation Curing}

The hydration process in cement concrete yields the end products, mainly consisting of C-S-H gel and free lime of $28 \%$ by volume. Carbonation happens only in the favorable environmental condition, i.e. at a temperature of $25-27^{\circ} \mathrm{C}$ and relative humidity of 50
$70 \%$. Based on this concept, $50 \%$ of test specimens after one day of initial ambient curing were weighed before carbonation and then placed in an air tight chamber and carbonated with pure $\mathrm{CO}_{2}$ gas at 1.5 bar pressure for 12 hours. The final mass of carbonated specimen and water accumulated in the chamber were calculated. After carbonation the test specimens were taken out and weighed. Then the carbonated test specimens were cured under moist curing to undergo the further hydration process till the testing for compressive strength at the age of 7 days, 14 days and 28 days. The schematic experimental setup for carbonation and compression test is presented in figs. 1 and 2, respectively.

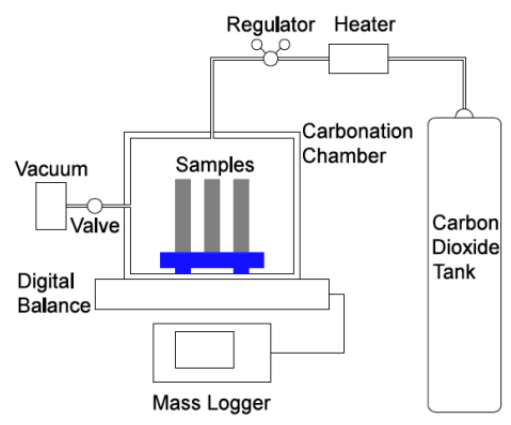

Fig. 1: Schematic Setup of Carbonation

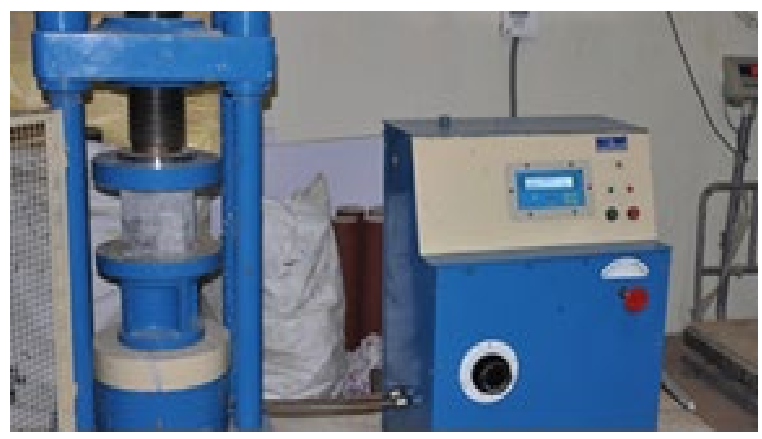

Fig. 2: Experimental setup for Compression Test

\section{Result and Discussion}

\subsection{Compression Test}

The compression tests were carried out in accordance with IS: 516-1953 and the samples of size $100 \times 100 \times 100 \mathrm{~mm}$ at the loading rate of $140 \mathrm{~kg} / \mathrm{cm}^{2} / \mathrm{min}$. tested at the age of 7 days, 14 days and 28 days for both reference and carbonated specimens. The compressive strength results and percentage increase of strength in concrete at the age of 3days, 7 days, and 28 of concrete are presented in Table 2 . The results of variation of compressive strength of test specimens tested at the age of 3 days, 7 days and 28 days are shown in Figs. 3, 4 and 5. The depth of carbonation was measured for each broken cube and the Phenolphthalein indicator solution was sprayed over the cut portion. The carbonated portion of the concrete became colourless $(\mathrm{pH}<9)$ and the non-carbonated portion shows pink in colour. The cross section of test specimen after carbonation is shown in Fig. 6. As per mass gain method, the $\mathrm{CO}_{2}$ uptake percentage is calculated by the formula as given below.

$\mathrm{CO}_{2}$ uptake $\%=\left(\mathrm{W}_{\text {after carbonation }}+\mathrm{W}_{\text {water lost }}\right)-\mathrm{W}_{\text {before carbonation }}$ $\mathrm{W}$ Cement 
Table 2: Mix Proportions for various grade concrete, compressive strength and $\mathrm{CO}_{2}$ uptake

\begin{tabular}{|c|c|c|c|c|c|c|c|c|c|c|c|}
\hline \multirow{3}{*}{ Mix } & \multirow{3}{*}{$\begin{array}{l}\text { Water } \\
\left(\text { lit }^{\prime} \mathbf{m}^{3}\right)\end{array}$} & \multirow{3}{*}{$\begin{array}{l}\text { Cement } \\
\left(\mathrm{kg} / \mathrm{m}^{3}\right)\end{array}$} & \multirow{3}{*}{$\underset{\left(\mathrm{kg} / \mathbf{m}^{3}\right)}{\text { F.A }}$} & \multirow{3}{*}{$\underset{\left(\mathrm{kg} / \mathrm{m}^{3}\right)}{\mathrm{C} \cdot \mathrm{A}}$} & \multicolumn{6}{|c|}{ Avg. Comp. strength of concrete $\left(\mathrm{N} / \mathrm{mm}^{2}\right)$} & \multirow{3}{*}{$\begin{array}{c}\mathrm{CO}_{2} \\
\text { Uptake } \\
\%\end{array}$} \\
\hline & & & & & \multicolumn{3}{|c|}{ Reference } & \multicolumn{3}{|c|}{ Carbonated } & \\
\hline & & & & & 3 day & 7 days & 28 davs & 3 day & 7 days & 28 days & \\
\hline M15 & 181.7 & 310.0 & 666.1 & 1200 & $\begin{array}{c}6.0 \\
(33.71 \%)\end{array}$ & $\begin{array}{c}10.7 \\
(60.11 \%)\end{array}$ & $\begin{array}{c}17.8 \\
(100 \%)\end{array}$ & $\begin{array}{c}17 \\
(87.17 \%)\end{array}$ & $\begin{array}{c}18.5 \\
(94.87 \%)\end{array}$ & $\begin{array}{c}19.5 \\
(100 \%)\end{array}$ & 12.5 \\
\hline M20 & 182.4 & 372.0 & 608.6 & 1202.9 & $\begin{array}{c}8.0 \\
(33.61 \%)\end{array}$ & $\begin{array}{c}14.0 \\
(58.82 \%)\end{array}$ & $\begin{array}{c}23.8 \\
(100 \%)\end{array}$ & $\begin{array}{c}12 \\
(50 \%)\end{array}$ & $\begin{array}{c}18.0 \\
(75 \%)\end{array}$ & $\begin{array}{c}24.0 \\
(100 \%)\end{array}$ & 11.0 \\
\hline M25 & 184.1 & 465.0 & 545.1 & 1184.6 & $\begin{array}{c}10.0 \\
(34.84 \%)\end{array}$ & $\begin{array}{c}15.2 \\
(52.96 \%)\end{array}$ & $\begin{array}{c}28.7 \\
(100 \%)\end{array}$ & $\begin{array}{c}16 \\
(55.17 \%)\end{array}$ & $\begin{array}{c}18.0 \\
(62.06 \%)\end{array}$ & $\begin{array}{c}29.0 \\
(100 \%)\end{array}$ & 2.5 \\
\hline MBO & 188.8 & 472.2 & 555.5 & 1194.4 & $\begin{array}{c}12.0 \\
(32.69 \%)\end{array}$ & $\begin{array}{c}20.5 \\
(55.85 \%)\end{array}$ & $\begin{array}{c}36.7 \\
(100 \%)\end{array}$ & $\begin{array}{c}17.5 \\
(47.29 \%)\end{array}$ & $\begin{array}{c}20.0 \\
(54.05 \%)\end{array}$ & $\begin{array}{c}37.0 \\
(100 \%)\end{array}$ & 2.1 \\
\hline
\end{tabular}

Note: Values given in the table are average of three identical specimens

Values given in bracket are \% strength development with reference to 28 days strength

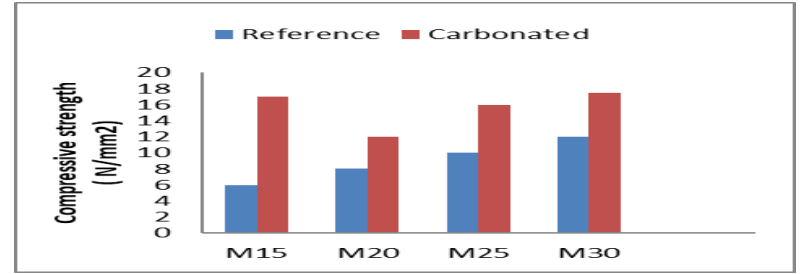

Fig. 3: Variation of Compressive Strength of concrete (3 days)

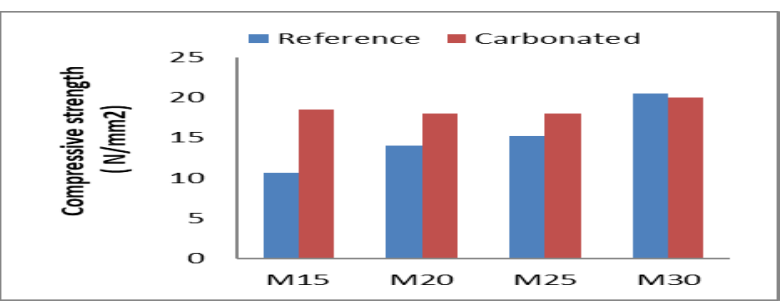

Fig. 4: Variation of Compressive Strength of concrete (4 days)

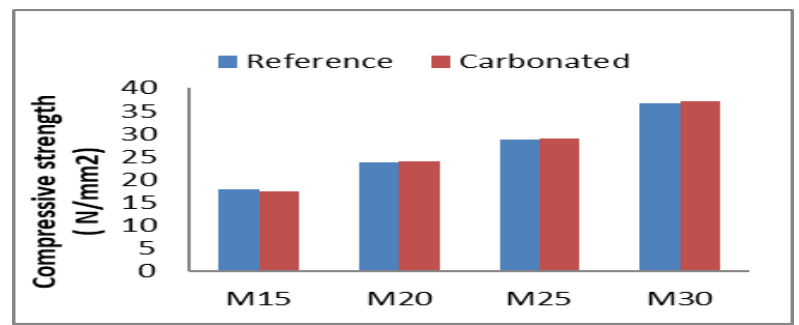

Fig. 5: Variation of Compressive Strength (28 days)

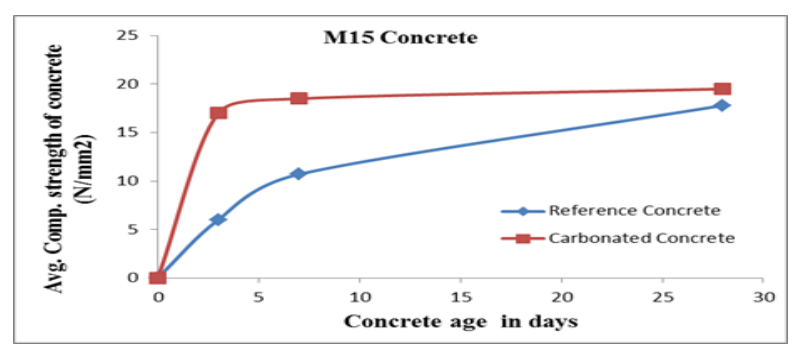

Fig. 6: Cross section of Specimen after carbonation

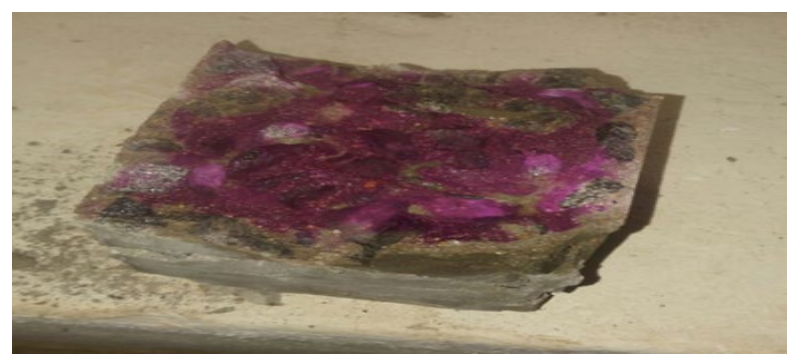

Fig. 7: Avg. Compressive strength Vs Age (M15)

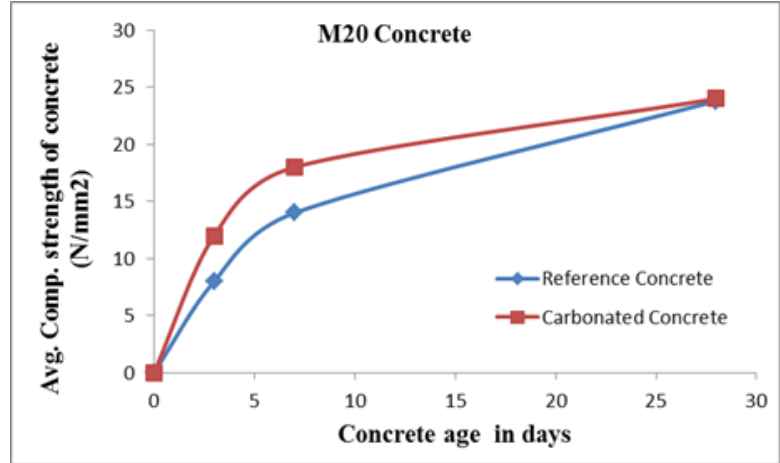

Fig. 8: Avg. Compressive strength Vs Age (M20)

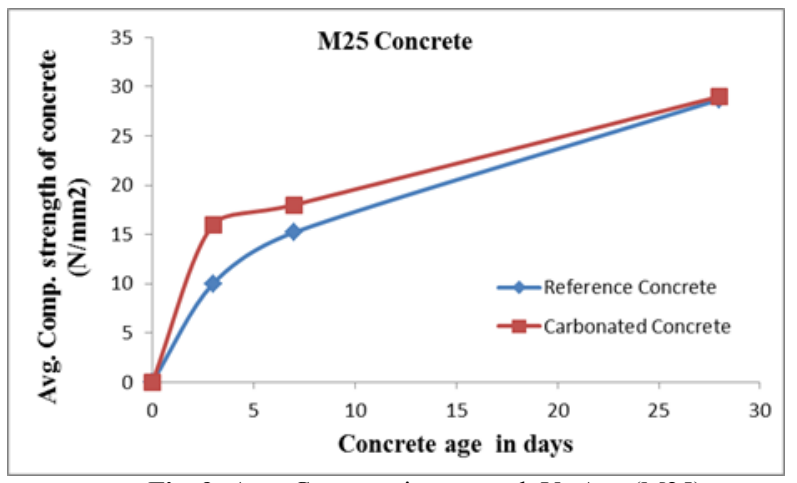

Fig. 9: Avg. Compressive strength Vs Age (M25)

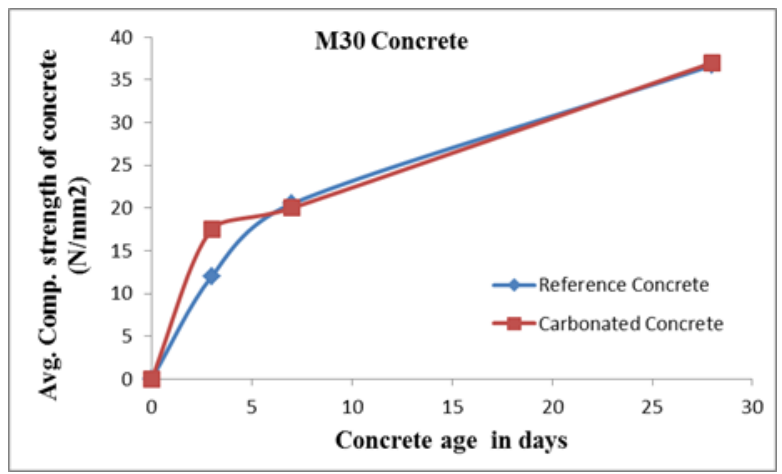

Fig. 10: Avg. Compressive strength Vs Age (M30)

The initial curing was necessary in the accelerated carbonation test to remove free water and facilitate and $\mathrm{CO}_{2}$ diffusion to favor the condition of carbonation. The water evaporated during carbonation was in the range of 2 to $5 \%$ which was much less than water removed by pre conditioning. The higher $\mathrm{W} / \mathrm{C}$ ratio concretes provided more permeable voids for $\mathrm{CO}_{2}$ to penetrate which could also have more evaporated water over carbonation. The water loss was compensated by moist curing to that play a critical role in the 
late strength development. From the figure 3, 4 and 5 it is observed that the M15 concrete with $\mathrm{W} / \mathrm{C}$ ratio equal to 0.6 sequestered more $\mathrm{CO}_{2}$ compared to the concrete with subsequent lesser W/C. Even though the cement content of the M15 concrete is less than the higher grade concrete the carbonation was comparatively more due to presence of more pore volume. In the higher grade concretes the carbonation process was found to be less due to less pore volume and the strength gain was due to the subsequent hydration process.

The average compressive strength of both reference and carbonated concrete test specimens versus age are shown in Fig.7 to 10 for M15, M20, M25 and M30 concrete respectively. From the table .2 and the above graphs shown in figs.7-10 it is concluded that the early age strength (3days) due to carbonation for M15 concrete is about $87.1 \%$ of 28 days compressive strength but the same for M20, M25 and M30 are 50\%, 55.17\% and 47.29\% respectively. The compressive strength of the above four grades of carbonated concrete for 7 days due to moist curing has been found as $94.87 \%, 75 \%, 62.06 \%$ and $54.06 \%$ of 28 days strength concerned concrete respectively. The depth of carbonation for M15 concrete are measured in the range of 10 to $12 \mathrm{~mm}, \mathrm{M} 20$ concrete 3 to 5 $\mathrm{mm}, \mathrm{M} 25$ concrete 1 to $2 \mathrm{~mm}$ and M30 concrete not measurable. The improved early age strength would be helpful in enhance the speed of construction. The strength achieved and $\mathrm{CO} 2$ uptake in lower grade concrete is comparatively higher than the other higher grade concrete.

\subsection{XRD Analysis}

A typical XRD analysis results for both reference and carbonated concrete is shown in Figs. 10 and 11 respectively. The inferences are made for M20, M25 and M30 concrete powdered samples as detailed below.

\section{M20R (Reference concrete)}

The X-ray Diffraction data of the sample M20R shows the formation of standard Silicon dioxide phase in majority. But the presence of calcium in the form of calcium hydroxide is also confirmed through X-ray data. This is possible due to the reaction of calcium when treated with water in certain conditions.

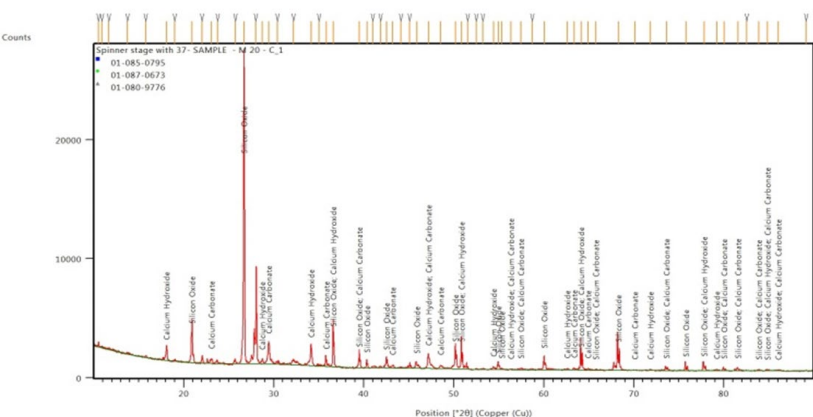

Fig. 11: Shows typical XRD analysis of M20 concrete before carbonation

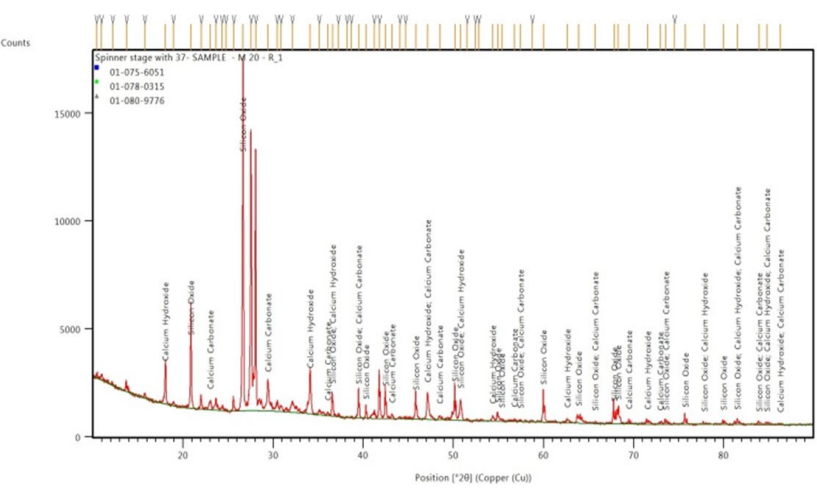

Fig. 12: Shows typical XRD analysis of M20 concrete after carbonation

\section{M20C (Carbonated concrete)}

The X-ray Diffraction data of the sample M20C shows the formation of majority Silicon dioxide phase in the material. The calcium exists in two different phases: calcium hydroxide and calcium carbonate, is confirmed. This is possible due to the reaction of calcium when treated with water and $\mathrm{CO}_{2}$ in certain conditions.

The findings from XRD are supported by the SEM micrographs for the sample M20C with the appearance of flake and layer like material. The layer by layer and flake like morphology is formed by the $\mathrm{SiO}_{2}$ phase in the material. The presence of white particles distributed in the morphology is observed to be calcium-based phases, i.e., calcium hydroxide and calcium carbonate. The observed particle size distribution calcium hydroxide and calcium carbonate particles of that the calcium hydroxide particles are in the range of $250 \mathrm{~nm}-700 \mathrm{~nm}$ size distribution.

\section{M25C}

The X-ray Diffraction data of the sample M25C shows the formation of standard Silicon dioxide phase in majority. The presence of calcium in the form of calcium carbonate along with calcium oxide silicate is confirmed through X-ray data. This is possible due to the reaction of calcium when treated with $\mathrm{CO}_{2}$ in certain conditions.

The findings from XRD is supported by the SEM micrographs for the sample $\mathrm{M} 25 \mathrm{C}$ with the appearance of flake like material. The layer by layer flake like morphology is formed by the $\mathrm{SiO}_{2}$ phase in the material and the white particles are the calcium carbonate along with calcium oxide silicate. Also, it is observed that the calcium carbonate and calcium oxide silicate particles are in the range of $300 \mathrm{~nm}-600 \mathrm{~nm}$ size distribution.

\section{M30C}

The X-ray Diffraction data of the sample M30C shows the formation of majority Silicon dioxide phase in the material. The calcium exists in two different phases: calcium carbonate and calcium manganese oxide, is confirmed. This is possible due to the reaction of calcium when treated with water and $\mathrm{CO}_{2}$ and manganese in certain conditions.

The findings from XRD is supported by the SEM micrographs for the sample M30C with the appearance of flake and layer like material. The layer by layer and flake like morphology is formed by the $\mathrm{SiO}_{2}$ phase in the material. The presence of white particles distributed, which is very less when compared to other samples, in the morphology is observed to b calcium-based phases, i.e., calcium carbonate and calcium manganese oxide. The observed particle size distribution calcium carbonate and calcium manganese oxide particles of that the calcium hydroxide particles are in the range of $200 \mathrm{~nm}-400 \mathrm{~nm}$ size distribution

The findings from XRD is supported by the SEM micrographs for the sample M20R with the appearance of flake like material. The layer by layer flake like morphology is formed by the $\mathrm{SiO}_{2}$ phase in the material and the white particles are the calcium hydroxide material. Also, it is observed that the calcium hydroxide particles are in the range of $300 \mathrm{~nm}-900 \mathrm{~nm}$ size distribution.

\section{M30R}

The X-ray Diffraction data of the sample M30R shows the formation of standard Silicon dioxide phase in majority. The presence of calcium in the form of calcium carbonate along with calcium hydroxide is confirmed through X-ray data. This is possible due to the reaction of calcium when treated with water and $\mathrm{CO} 2$ in certain conditions.

The findings from XRD are supported by the SEM micrographs for the sample M30R with the appearance of flake like material. 
The layer by layer flake like morphology is formed by the $\mathrm{SiO}_{2}$ phase in the material and the white particles are the calcium carbonate along with calcium hydroxide. Also, it is observed that the calcium carbonate and calcium oxide silicate particles are in the range of $150 \mathrm{~nm}-450 \mathrm{~nm}$ size distribution.

\section{Conclusion}

The accelerated early carbonation causes the formation of $\mathrm{CaCO} 3$ due to the reaction between $\mathrm{CO} 2$ and $\mathrm{C} 3 \mathrm{~S}, \mathrm{C} 2 \mathrm{~S}$ from surface to inward causes the closure of micro as well as macro pores. The secondary reaction between $\mathrm{CO} 2$ and initially formed $\mathrm{Ca}(\mathrm{OH}) 2$ also yields the end product as $\mathrm{CaCO} 3$ to cause discontinuity of capillary pores which helps in enhance the compressive strength as well as reduce the permeability due to the reduction of pore volume.

The early age carbonation in the concrete blocks the pores on the surface to inward to smaller depth in the cover concrete protects the weathering carbonation in the long run further due to prolonged hydration yields the end product as C-S-H gel and $\mathrm{Ca}(\mathrm{OH}) 2$.This free lime maintains the alkalinity which is favoring the passive layer over the surface of the rebars to protect and enhance the life of higher grade precast units.

The early carbonation is helpful in conserving the water instead of going for steam curing for precast units. The percentage of strength enhancement and uptake of $\mathrm{CO} 2$ is found to be higher in low grade concrete and less in higher grade concrete.

The accelerated carbonation will be very suitable for construction masonry units, fiber boards like precast units of large scale manufacturing purposes.

The other cementitious materials with calcium oxide and silicate content can also be used as a partial replacement of cement to reduce $\mathrm{CO} 2$ foot prints. XRD analysis conforms the mineral conversion due to carbonation and particle size distribution.

\section{Summary}

Based on the trial experiment conducted in the laboratory, the following conclusions are obtained. The uptake quantity of $\mathrm{CO} 2$ is more in the lower grade concrete having higher water to cement ratio and is getting reduced with respect to low water to cement ratio. The early strength gain in the lower grade concrete is due to more pore space created due to water loss in the concrete. In the higher grade concrete, due to low water to cement ratio, the pore volume is less and the possibility of carbonation from the surface is getting reduced, and the depth of carbonation also getting reduced. It is concluded that the $\mathrm{CO} 2$ sequestration is more suitable for plain cement concrete precast units. Photos must be crystal clear with such resolution to allow fine details visibility. The elements from any photo must be explained using numbers, letters, etc. The text within a figure or photo must have the same style, shape and height as the caption has.

\section{References}

[1] Adina Bosoaga, OndrejMasek, John E. Oakey," $\mathrm{CO}_{2}$ Capture Technologies For Cement Industry" Science Direct, Energy Procedia 1(2009),pp 133-140

[2] BerendSmit, Ah-HyungAlissa Park And GreeshmaGadikota,U.S., "The Grand Challenges In Carbon Capture, Utilization, and Storage",- frontiers in ENERGY RESEARCH-Specialty Grand Challenge Article, November 2014, Pp1-5

[3] HilalEi-Hassan and YixinShao,"Carbon Storage Through Concrete Block Carbonation Curing,"- Journal Of Clean Energy Technologies, Vol.2,No. 3, July 2014,pp287-291

[4] Kazuya Goto, FirozAlamChowdhury, Hiromichi Okabe, Shinkichi Shimizu and Yuichi Fujioka,(2011). "Development of a Low Cost
$\mathrm{CO}_{2}$ Capture System with a Novel Absorbent under the COCS Project,"Science Direct, Energy Procedia 4(2011),pp 253-258

[5] Lana Tayara, Master Thesis on "Feasibility Analysis For Carbon Capture And Utilization In Cement-Concrete Industries" Department of Civil Engineering \& Applied Mechanics, McGill University ,Canada in 2012

[6] NETL,the energy lab project facts - Carbon Storage- $\mathrm{CO}_{2}$ use and reuse ,(2013),"Beneficial Use Of $\mathrm{Co}_{2}$ In Precast Concrete Products"FE0004285,May 2013

[7] Profiles, IEA Clean Coal Centre, Gemini House, 10-18 Putney Hill, London, U.K. -No.11/6, report on $\mathrm{CO}_{2}$ abatement in the cement industry, Qian Zhu,85pp. June 2011

[8] Prof.PeterClaisse of Coventry University, U.K.(2013), 'Capturing Carbon with concrete"-Carbon Capture Journal, September ,2013

[9] S.O.Ogbeide,(2010),"Developing an optimization model for $\mathrm{CO}_{2}$ reduction in cement production process", Journal of Engineering 3Science and Technology Review 3(1),April 2010

[10] Sean Monkman, "Technical note - Types of Concrete Carbonation", CarbonCure Technologies Inc $\mid 60$ Trider Crescent, Dartmouth, NS, B3B 1R6.info@carboncure.com

[11] UlhasParlikar,(2014), "Technological Advancements For Manufacturing Cement In An Ecologically Sustaining Manner In The Future",pp33-41, October 2014

[12] Y.Shao, S.Monkman and A.J. Boyd,"RecyclingCarbondioxide Into Concrete: A Feasibility Study "-Concrete Sustainability Conference,2010,pp1-10 